\title{
The Internet: home to a severe population of individuals with social anxiety disorder? is $^{\text {s }}$
}

\author{
Brigette A. Erwin ${ }^{\mathrm{a}, *}$, Cynthia L. Turk ${ }^{\mathrm{a}, 1}$, \\ Richard G. Heimberg ${ }^{\mathrm{a}}$, David M. Fresco ${ }^{\mathrm{a}, 2}$, \\ Donald A. Hantula ${ }^{\mathrm{b}}$ \\ aAdult Anxiety Clinic, Department of Psychology, Temple University, Philadelphia, PA, USA \\ ${ }^{\mathrm{b}}$ Department of Psychology, Temple University, Philadelphia, PA, USA
}

Received 9 July 2003; accepted 5 August 2003

\begin{abstract}
The current study sought to understand better the psychological characteristics of socially anxious individuals who seek information on the internet about social anxiety disorder and its treatment. Participants were 434 individuals who responded to an internet-based survey linked to the website of an anxiety specialty clinic. Using established cut-off scores, $92 \%$ of the sample met criteria for social anxiety disorder. Internet survey respondents who met these criteria reported greater severity of and impairment due to social anxiety than a treatmentseeking sample of persons with social anxiety disorder. Nevertheless, only about one-third of these internet respondents reported having received psychotherapy, and a similar percentage reported having received pharmacotherapy. Those with the most severe social interaction anxiety and who spent the most time interacting on the internet endorsed positive effects of internet use. However, a significant number of negative effects also were endorsed.
\end{abstract}

(C) 2003 Elsevier Inc. All rights reserved.

Keywords: Social anxiety disorder; Social phobia; Internet-based survey; Web-based survey

\footnotetext{
${ }^{t}$ Portions of this paper were presented at the annual meetings of the Association for Advancement of Behavior Therapy, New Orleans, LA, November, 2000

* Corresponding author. Present address: University of Pennsylvania School of Medicine, Department of Psychiatry, 11 Gates, 3400 Spruce Street, Philadelphia, PA 19104, USA.

E-mail address: berwin@mail.med.upenn.edu (B.A. Erwin).

${ }^{1}$ Present address: La Salle University, Department of Psychology, Philadelphia, PA, USA.

${ }^{2}$ Present address: Kent State University, Department of Psychology, Kent, OH, USA.
} 
Contemporary cognitive-behavioral models of social anxiety disorder (Clark \& Wells, 1995; Rapee \& Heimberg, 1997) propose that, in the presence of others, affected individuals form negatively biased thoughts and images about their appearance (e.g., overestimate visibility of anxiety symptoms, exaggerate physical flaws) and behavior (e.g., overestimate speech dysfluencies, demean contributions to conversations). These thoughts and images lead individuals with social anxiety disorder to judge negative evaluation from others to be highly likely. Individuals with social anxiety disorder often resolve the conflict between their need for social contact and their desire to avoid painful feelings they anticipate from interpersonal interactions in favor of avoidance and social isolation. Not surprisingly, individuals with social anxiety disorder describe their relationships with family, friends, and romantic partners as impaired (Schneier et al., 1994; Turner, Beidel, Dancu, \& Keys, 1986; Whisman, Sheldon, \& Goering, 2000). For socially anxious individuals, communicating with others on the internet in a text-based manner (i.e., email, chat rooms, instant messaging) may allow them to avoid aspects of social situations they fear (e.g., blushing, stammering, others' reactions to perceived physical or social shortcomings) while at the same time to partially meet their needs for interpersonal contact and relationships.

In the last 10 years, the internet has become increasingly accessible to a sizable proportion of U.S. households. As of March 2003, there were approximately 649 million people globally and 173 million people in the United States with internet access (Global Reach, 2003). The advantages of internet communication are many, such as access to a wider network of people with similar interests or concerns and increased ability to stay in touch with geographically distant friends and family. In one study that demonstrates the potential benefit of internet communication, Cummings, Sproull, and Kiesler (2002) examined participants of a discussion group for individuals with hearing loss. Individuals with less real-world support participated more actively in the discussion group, and active participation was associated with greater reported benefits derived from the group. Additionally, participants who reported having a family member or friend participate in the discussion group, thus integrating face-to-face and online support networks, reported deriving even greater benefits from the discussion group.

Although positive correlates of internet use are numerous, awareness of potential disadvantages of internet communication is growing. Kraut and colleagues (1998) examined the effect of internet usage on 169 individuals in 73 households during their first 1-2 years online. From pre-internet access to postinternet access, greater use of the internet was associated with declines in family communication, decreases in the size of participants' local and distant social circles, and increases in depression and loneliness. Kraut and colleagues speculated that, although most internet usage is devoted to active social communication, internet usage actually might reduce face-to-face contact, such that weaker social relationships supplant stronger ones. A 3-year follow-up study, however, found that these negative effects of internet usage had dissipated (Kraut et al., 2002). 
The authors noted that, during the intervening 3 years, internet access in the home quadrupled and new communication services such as instant messaging evolved, making it easier to develop and maintain strong social bonds with family and friends via internet communication. Additionally, greater access to health, financial, hobby, and consumer information and services may have allowed individuals to better integrate the internet into their lives.

Research suggests that internet use may have different consequences for people with different personality traits, although findings regarding internet use and personality characteristics have been inconsistent (cf. Hills \& Argyle, 2003; Swickert, Hittner, Harris, \& Herring, 2002). Negative outcomes of internet use may be moderated by personality traits and usage patterns. Kraut and colleagues (2002) assessed a sample of new computer purchasers with internet access three times over the course of a year. For the full sample, participants who used the internet more had generally positive outcomes, including increases in the size of their local and distant social circles, increased face-to-face interactions with family and friends, greater trust in other people, and increased positive affect. However, when the interaction between internet use and introversion-extraversion was examined, positive outcomes were observed for extraverts using the internet extensively, but negative outcomes were observed for introverts using the internet extensively. Specifically, introverts who frequently used the internet reported less community involvement, increased loneliness, increased negative affect, increased time pressure, and decreased self-esteem over the course of the study relative to introverts who rarely used it. Extraverts using the internet extensively showed the opposite pattern of outcomes. Further, extraversion was found to be positively associated with using the internet to keep up with family and friends and meeting new people online, although these associations were weak. In another study, socially anxious adolescents were more likely to communicate online with people with whom they did not have a close relationship and to talk about less intimate topics, and social anxiety was positively correlated with communicating with others on the internet to avoid being alone (Gross, Juvonen, \& Gable, 2002).

Thus, as Gross and colleagues (2002) suggest, the internet may undermine or foster well being depending on whether it shrinks or enhances opportunities for meaningful, daily, face-to-face contact with others. For extraverted or socially comfortable individuals, internet use may be another way to maintain and enhance social relationships. However, in the case of introverted or socially anxious individuals, internet use may serve as a way to avoid being alone and may intensify disconnection from face-to-face relationships. Since research suggests that relationships developed and maintained online are typically not as close as those formed and maintained offline (Cummings, Butler, \& Kraut, 2002; Gross et al., 2002), socially anxious and introverted individuals using internet communications as a substitute for face-to-face relationships seem unlikely to succeed in getting their interpersonal needs fully met.

The current study sought to understand better the psychological characteristics of socially anxious individuals who seek information on the internet about social 
anxiety disorder and its treatment. Of particular interest were the severity of symptoms and degree of impairment reported by these individuals, many of whom were expected never to have accessed treatment. Also of interest were positive and negative correlates of social internet use as judged by these socially anxious individuals.

\section{Method}

\subsection{Participants and procedures}

Internet participants were 140 men, 291 women, and 3 individuals who did not provide information on sex (total $N=434$ ), who responded to a survey posted on the internet entitled "Social Anxiety Disorder and the Internet." The survey was posted on the Adult Anxiety Clinic of Temple University (AACT) webpage (www.temple.edu/phobia), which is accessible through search engines and is linked to other anxiety and social anxiety disorder webpages. A link to the survey was also posted on the website of the Anxiety Disorders Association of America (www.adaa.org). The survey was posted from December 1999 through July 2001, and 498 responses were received. All participants accepted the terms of a consent statement before they were able to access the survey. Internet respondents were required to affirm that they were at least 18 years of age. Potential participants were assured of anonymity. Multiple identical responses and responses with significant incomplete data were monitored by visual inspection of each entry and were excluded from the data analyses $(n=64)$.

Two comparison groups were included in this study. The first group was a sample of individuals who sought treatment at the AACT for interpersonal and performance anxiety (AACT patients; $n=229$ ). These patients underwent a semi-structured diagnostic interview, the Anxiety Disorders Interview Schedule for DSM-IV-Lifetime Version (ADIS-IV-L; DiNardo, Brown, \& Barlow, 1994) and received a principal diagnosis of $D S M-I V$ social anxiety disorder. They may also have met criteria for additional psychiatric diagnoses. AACT patients with principal diagnoses other than social anxiety disorder or with comorbid diagnoses of schizophrenia, substance abuse or dependence, clinically significant depression that was associated with prominent risk of self-harm, or organic mental disorder were excluded. The second comparison group was comprised of individuals who were recruited from the greater Philadelphia community and paid to participate in a study of persons without significant psychological distress (AACT controls; $n=36$ ). AACT controls were recruited in such a way that they would closely reflect the AACT patient sample on the demographic characteristics of age, race, and sex. AACT controls were interviewed with the ADIS-IV-L and met no criteria for current Axis I diagnoses other than, in one case, specific phobia. Subsequent to completion of the diagnostic interview and, for patients, prior to the commencement of 
treatment, AACT patients and controls completed the questionnaires described below.

\subsection{Materials}

\subsubsection{Internet survey design}

The internet survey was designed to be accessible to as many potential participants as possible. To avoid excessive download times (Rajala \& Hantula, 2000; Rose, Lees, \& Meuter, 2001) and to decrease the probability of participants dropping out midway through the survey (Dillman, Totora, Conradt, \& Bowker, 1998), it featured a plain design largely of text with minimal graphics, and each section of the survey loaded as a new page. The survey was tested with both Internet Explorer and Netscape browsers.

\subsubsection{Assessment of demographics}

Information about participants' age, sex, race, continent of residence, marital status, educational attainment, employment status, and annual income was obtained.

\subsubsection{Assessment of internet use}

This measure, created by the study investigators, assessed which applications (i.e., chat rooms, list serves, newsgroups, e-mail, browsing) internet participants typically used and asked participants to indicate on a 5-point categorical scale the amount of time per week that they spent using each of those applications. Additionally, this measure asked participants to rate on a 5-point Likert-type scale, from 1 (not true for me) to 5 (extremely true for me), several items related to the degree to which (a) they received social support on the internet; (b) the internet provided information that led them to understand more fully and to seek treatment for their social anxiety; (c) they communicated with others on the internet so as to avoid face-to-face interactions; (d) the use of the internet strengthened their maladaptive beliefs; and (e) they feared negative evaluation from others with whom they communicated on the internet.

\subsubsection{Assessment of clinical and impairment variables}

Current and past treatment utilization was assessed through administration of a self-report measure designed by the study investigators. This measure queried whether internet respondents had ever received psychotherapy or pharmacotherapy or tried herbal remedies for social anxiety disorder.

An assessment of anxiety-provoking social situations was conducted by administering a self-report measure modeled after an instrument utilized in a study conducted by Stein, Walker, and Forde (1994). Participants were asked how nervous or uncomfortable they would be speaking in front of a large audience, speaking in front of a small group of familiar people, using a public restroom, speaking to persons in authority, talking to others due to a concern of having 
nothing to say or sounding foolish, writing in front of others, eating in front of others, speaking to strangers or meeting new people, participating in meetings or classes, and attending social gatherings. In addition, participants were asked about the date of onset and, if applicable, date of remission of these concerns, and the extent to which they caused interference or distress.

Participants completed questionnaires that assess social anxiety and associated disability. The Social Interaction Anxiety Scale (SIAS) and the Social Phobia Scale (SPS; Mattick \& Clarke, 1998) measure anxiety in dyads and groups and in situations in which the person may be critically observed by others, respectively. Both the SIAS and SPS consist of 20 items $^{3}$ that are rated on a 5-point Likert-type scale from 0 (not at all characteristic) to 4 (extremely characteristic). Sample SIAS items include 'I feel I will say something embarrassing when talking' and 'I have difficulty making eye contact with others.' Sample SPS items include 'I get nervous that people are staring at me as I walk down the street' and 'I worry I might do something to attract the attention of other people.' Both the SIAS and the SPS have been shown to be reliable instruments for the assessment of social anxiety disorder and to possess a high degree of convergent validity with other indices of social anxiety and avoidance (Brown et al., 1997; Heimberg, Mueller, Holt, Hope, \& Liebowitz, 1992; Mattick \& Clarke, 1998). Cut scores on the SIAS designed to optimize sensitivity and specificity were employed to determine which internet respondents likely would have met criteria for social anxiety disorder (SIAS cutscore $\geq 34$; Brown et al., 1997; Heimberg et al., 1992) and for the generalized subtype of social anxiety disorder (SIAS cutscore $\geq 42$; Hart, Fresco, Turk, \& Heimberg, 2000).

The Liebowitz Self-Rated Disability Scale (LSRDS; Schneier et al., 1994) is an 11-item self-report inventory designed to assess disability in social anxiety disorder. Items are rated on a scale from 0 (problem does not limit me at all) to 3 (problem limits me severely). Current (during the past 2 weeks) and lifetime (lifetime/when I was as my worst) impairment are separately assessed in the following domains: alcohol use, other substance use, mood, education, work, family relationships, romantic relationships, social relationships, hobbies, activities of daily living, and desire to live. The LSRDS demonstrates high internal consistency and good concurrent validity with other measures of impairment among patients with social anxiety disorder. Studies of individuals with social anxiety disorder that have included the LSRDS as a measure of disability demonstrated that social anxiety disorder was associated with pervasive disability, impairing education, career, and romantic relationships in particular (e.g., Hambrick, Turk, Heimberg, Schneier, \& Liebowitz, in press, 2003; Schneier et al., 1994; Wittchen, Fuetsch, Sonntag, Muller, \& Liebowitz, 1999). The LSRDS was not completed by AACT control participants since its instructions ask respondents to rate the degree to which "their emotional problem" causes them difficulty.

\footnotetext{
${ }^{3}$ Two versions of the SIAS are currently available, one with 19 items, the other with 20 items. We used the 20-item version, which has been much more commonly used in published research.
} 


\section{Results}

\subsection{Characteristics of internet survey respondents}

The mean age of the internet survey respondents was $31.85($ S.D. $=11.11)$. Of the total sample, $67.05 \%$ were female, and $53.69 \%$ were never married. In addition, the distribution of race (85.94\% Anglo; $4.38 \%$ Hispanic; $2.07 \%$ African; 2.07\% Asian; $0.69 \%$ Native American; $2.76 \%$ Other) and continent of origin (85.48\% North America; 6.22\% Europe; $2.07 \%$ Asia; $1.84 \%$ Australia; $0.92 \%$ South America) among internet respondents indicated that they were primarily of Anglo descent and residing in North America.

Fifty internet respondents $(11.52 \% ; n=50 / 434)$ did not supply information on the SIAS sufficient to allow determination of whether or not they should be categorized as having met criteria for social anxiety disorder. The criterion for social anxiety disorder (SIAS $\geq 34)$ was met by $92.19 \%(n=354 / 384)$ of the remaining participants. The large majority of internet respondents who met criteria for social anxiety disorder indicated that they experience anxiety, interference, and distress when exposed to formal public speaking $(85.03 \%)$; attending social gatherings $(84.18 \%)$; fearing that they will have nothing to say or will sound foolish $(79.94 \%)$; participating in meetings, classes, or going to parties (79.94\%); speaking to strangers $(77.68 \%)$; interacting in small groups $(74.58 \%)$, and interacting with authorities $(69.49 \%)$. Fewer respondents who met criteria for social anxiety disorder reported that they experience anxiety, interference, and distress when eating in public $(42.37 \%)$, writing in public $(34.46 \%)$, or using public restrooms $(28.81 \%)$. In addition, $76.84 \%$ of internet respondents who met criteria for social anxiety disorder reported socializing in person less than five hours per week; $36.44 \%$ reported having no significant friendships; and $46.33 \%$ reported having no romantic relationships. Finally, among internet respondents who met criteria for social anxiety disorder who resided predominately on the North American continent at the time they completed the study, 11.59\% (43/371) were unemployed and $65.23 \%$ (242/371) had not completed college.

\subsection{Symptoms of social anxiety and impairment among internet survey} respondents with social anxiety disorder and comparison samples

Comparisons of mean scores on the SIAS, SPS, LSRDS-Current, and LSRDSLifetime were made among internet survey respondents who met criteria for social anxiety disorder and AACT patients and controls (see Table 1). Internet respondents with social anxiety disorder scored significantly higher than AACT patients, who scored significantly higher than AACT controls, on both the SIAS and SPS. Internet respondents with social anxiety disorder also scored significantly higher than did AACT patients on LSRDS-Current. Internet respondents with social anxiety disorder and AACT patients did not differ on LSRDSLifetime. Among internet respondents with social anxiety disorder, greater 
Table 1

Social anxiety and impairment among internet survey respondents with social anxiety disorder, clinic patients with social anxiety disorder, and normal controls

\begin{tabular}{|c|c|c|c|c|c|c|c|}
\hline & \multirow{2}{*}{\multicolumn{2}{|c|}{$\begin{array}{l}\text { Social anxiety disorder } \\
\text { Internet survey } \\
\text { respondents }(n=354)\end{array}$}} & \multicolumn{4}{|c|}{ Adult Anxiety Clinic of Temple } & \multirow[t]{3}{*}{$F$} \\
\hline & & & \multicolumn{2}{|c|}{ Patients $(n=229)$} & \multicolumn{2}{|c|}{ Controls $(n=36)$} & \\
\hline & $M$ & S.D. & $M$ & S.D. & $M$ & S.D. & \\
\hline SIAS & $58.93 \mathrm{a}$ & 12.72 & $48.99 \mathrm{~b}$ & 15.52 & $11.67 \mathrm{c}$ & 9.32 & $209.48^{* * * *}$ \\
\hline \multirow[t]{2}{*}{ SPS } & $45.33 \mathrm{a}$ & 17.14 & $30.79 \mathrm{~b}$ & 15.77 & $4.61 \mathrm{c}$ & 5.94 & $131.44^{* * * *}$ \\
\hline & $M$ & S.D. & $M$ & S.D. & & & $t$ \\
\hline LSRDS-Current & 11.35 & 6.09 & 8.96 & 5.34 & - & - & $4.74^{* * * *}$ \\
\hline LSRDS-Lifetime & 16.12 & 6.70 & 15.30 & 7.10 & - & - & 1.32 \\
\hline
\end{tabular}

Note. SIAS $=$ Social Interaction Anxiety Scale; SPS $=$ Social Phobia Scale; LSRDSCurrent $=$ Liebowitz Self-Rated Disability Scale-Current; LSRDS-Lifetime = Liebowitz Self-Rated Disability Scale-Lifetime. For the SIAS and SPS, means in the same row that do not share the same subscript differ at $P<.05$ in the Tukey HSD post hoc comparison. The LSRDS was not administered to control participants.

${ }^{* * * *} P<.001$.

amounts of time interacting on the internet $(M=5.59$, S.D. $=12.26$, range $=$ 0-100 h per week) were associated with greater scores on the LSRDS-Current $(r=.20, P<.01)$ and LSRDS-Lifetime $(r=.17, P<.05)$, but not the SIAS $(r=.03, n s)$ or SPS $(r=.01, n s)$. A greater proportion of internet respondents with social anxiety disorder $(88.14 \%)$ than AACT patients $(70.71 \%)$ was classified as having generalized social anxiety disorder (subtype of social anxiety disorder in both groups determined by SIAS $\geq 42 ; \chi^{2}(d f=1, n=552)=26.00$, $P<.001)$.

\subsection{Treatment history among internet survey respondents with social anxiety disorder}

Only $35.59 \%$ of internet survey respondents who met criteria for social anxiety disorder reported ever having received psychotherapy for social anxiety disorder. Similarly, only $35.03 \%$ reported ever having received pharmacotherapy for social anxiety disorder. Finally, $31.36 \%$ reported having tried herbal remedies for social anxiety disorder.

\subsection{Nature and kinds of internet use among internet survey respondents with social anxiety disorder}

The nature and kinds of internet use reported by internet survey respondents who met criteria for social anxiety disorder are presented in Table 2. Internet respondents with social anxiety disorder reported interacting actively with others 
Table 2

Nature and kinds of internet use among internet survey respondents with social anxiety disorder

\begin{tabular}{lcc}
\hline Nature of internet use & $M$ & S.D. \\
\hline Percent of internet time spent actively participating & 18.81 & 25.97 \\
Percent of internet time spent passively observing & 53.42 & 40.15 \\
Kinds of internet use & $n$ & Percent \\
\hline Engages in internet surfing & 336 & 94.92 \\
Uses e-mail & 334 & 94.35 \\
Uses listservs & 190 & 53.67 \\
Uses chatrooms & 121 & 34.18 \\
Uses newsgroups & 83 & 23.45 \\
\hline
\end{tabular}

Note. $N=354$.

less than $20 \%$ of the time they used the internet; they reported observing passively more than $50 \%$ of the time they used the internet.

\subsection{Self-rated positive effects of internet use among internet survey respondents with social anxiety disorder}

Table 3 presents the degree to which internet survey respondents with social anxiety disorder reported receiving social support and information from the internet and acting on the support and information that they received. Table 3 also presents the degree to which these reported benefits of internet use were associated with SIAS scores (the SIAS was selected for this purpose because of its specific focus on anxiety in social interactions) and the amount of time per week reportedly spent interacting on the internet. On average, internet respondents with social anxiety disorder reported that it was "moderately" to "very" true that they acquired new information about social anxiety through internet use $(M=3.79$, S.D. = 1.19) and learned about psychotherapy and medication treatments for social anxiety disorder through internet use $(M=3.61$, S.D. $=1.29)$.

After Bonferroni correction, scores on the SIAS were positively associated with endorsement of having received encouragement from others on the internet when sharing difficulties with social anxiety. In addition, SIAS scores were positively associated with endorsement of having acquired new information about social anxiety through internet use, having come to understand through internet use that social anxiety disorder is a treatable problem, and having learned through internet use about psychotherapy and medication treatments for social anxiety disorder.

After Bonferroni correction, the amount of time per week reportedly spent interacting on the internet was positively associated with endorsement of having received support and encouragement from others on the internet when sharing difficulties with social anxiety. In addition, the amount of time spent interacting on the internet was positively associated with endorsement of having developed 
Table 3

Self-rated positive effects of internet use among internet survey respondents with social anxiety disorder

\begin{tabular}{|c|c|c|c|c|}
\hline & $M$ & S.D. & SIAS $r$ & Time $r$ \\
\hline \multicolumn{5}{|l|}{ Social Support from the Internet } \\
\hline \multicolumn{5}{|l|}{ Internet use has led to } \\
\hline Support from others on the internet & 1.95 & 1.22 & .09 & $.36^{* * * *}$ \\
\hline $\begin{array}{l}\text { Encouragement regarding social anxiety from } \\
\text { others on the internet }\end{array}$ & 2.76 & 1.33 & $.21^{\dagger}$ & $.27^{\dagger}$ \\
\hline Development of new friendships & 2.27 & 1.41 & .10 & $.49^{* * *}$ \\
\hline Increased confidence when interacting face-to-face & 1.77 & 1.06 & -.09 & $.32^{* * * *}$ \\
\hline Strengthening of face-to-face friendships & 1.59 & 0.95 & .01 & .12 \\
\hline $\begin{array}{l}\text { Empathy regarding social anxiety from others } \\
\text { on the internet }\end{array}$ & 2.82 & 1.41 & .20 & .20 \\
\hline $\begin{array}{l}\text { Encouragement to confront anxiety-provoking } \\
\text { situations from others on the internet }\end{array}$ & 2.08 & 1.20 & .05 & .08 \\
\hline $\begin{array}{l}\text { Perception that the average person is tolerant of } \\
\text { those with social anxiety }\end{array}$ & 2.04 & 1.13 & .08 & .14 \\
\hline \multicolumn{5}{|l|}{ Internet provided information and led to action } \\
\hline \multicolumn{5}{|l|}{ Internet use has led to } \\
\hline Acquisition of new information about social anxiety & 3.79 & 1.19 & $.19^{* * * *}$ & .05 \\
\hline Seeking psychotherapy treatment for social anxiety & 1.76 & 1.25 & .13 & .07 \\
\hline Seeking medication treatment for social anxiety & 1.88 & 1.27 & .14 & .12 \\
\hline Obtaining self-help books mentioned on the internet & 1.97 & 1.36 & .01 & .06 \\
\hline Understanding that social anxiety disorder is treatable & 2.56 & 1.56 & $.32^{* * *}$ & .03 \\
\hline $\begin{array}{l}\text { Learning about psychotherapy and medication } \\
\text { treatments of social anxiety disorder }\end{array}$ & 3.61 & 1.29 & $.16^{\ddagger}$ & .10 \\
\hline Understanding that social anxiety is a common problem & 2.90 & 1.41 & .05 & .11 \\
\hline
\end{tabular}

Note. $N=354$. SIAS $r=$ correlation between the Social Interaction Anxiety Scale and individual items representing the self-rated positive effects of internet use. Time $r=$ correlation between the hours per week internet respondents reported interacting on the internet and individual items representing the self-rated positive effects of internet use. Items concerning the positive effects of internet use were rated on a 5-point Likert-type scale, from 1 (not true for me) to 5 (extremely true for $m e)$. Bonferroni-corrected $P$-values of $.006(.05 / 8)$ and $.007(.05 / 7)$ were employed in these analyses.

$$
\begin{aligned}
& { }^{* * * *} P<.001 . \\
& { }^{\dagger} P<.006 . \\
& { }^{\ddagger} P<.007 .
\end{aligned}
$$

through internet use new friendships and increased confidence when interacting face-to-face.

\subsection{Self-rated negative effects of internet use among internet survey respondents with social anxiety disorder}

Table 4 presents the degree to which internet survey respondents with social anxiety disorder reported that the internet increased avoidance of feared aspects of face-to-face interactions, strengthened maladaptive beliefs, and was associated with fear of negative evaluation by others on the internet. Table 4 also presents the 
Table 4

Self-rated negative effects of internet use among internet survey respondents with social anxiety disorder

\begin{tabular}{|c|c|c|c|c|}
\hline & $M$ & S.D. & SIAS $r$ & Time $r$ \\
\hline \multicolumn{5}{|c|}{ Internet increased avoidance of feared aspects of face-to-face interactions } \\
\hline \multicolumn{5}{|c|}{ I use the internet because } \\
\hline $\begin{array}{l}\text { Increased comfort interacting on the internet vs. } \\
\text { face-to-face }\end{array}$ & 3.41 & 1.40 & $.20^{* * *}$ & $.27^{* * *}$ \\
\hline $\begin{array}{l}\text { I talk about my problems more with people on } \\
\text { the internet than face-to-face }\end{array}$ & 2.45 & 1.52 & $.24^{* * * *}$ & $.42^{* * *}$ \\
\hline Others on the internet cannot hear mistakes in my speech & 2.33 & 1.37 & $.33^{* * *}$ & .15 \\
\hline $\begin{array}{l}\text { I have more time to think about what I want to } \\
\text { say than in a face-to-face conversation }\end{array}$ & 3.02 & 1.38 & $.33^{* * *}$ & .16 \\
\hline It is easier for me to avoid interacting face-to-face & 2.98 & 1.37 & $.35^{* * *}$ & .08 \\
\hline $\begin{array}{l}\text { It is easier to initiate and maintain conversations } \\
\text { than face-to-face }\end{array}$ & 2.90 & 1.44 & $.27^{* * * *}$ & $.39^{* * *}$ \\
\hline $\begin{array}{l}\text { I used to spend more time interacting with people } \\
\text { face-to-face before using the internet }\end{array}$ & 1.51 & .94 & -.02 & .07 \\
\hline Others cannot see visible signs of my anxiety & 3.14 & 1.49 & $.41^{* * *}$ & .13 \\
\hline Others cannot judge me by my physical appearance & 2.88 & 1.46 & $.36^{* * *}$ & .10 \\
\hline Encouraged to avoid anxiety-producing social situations & 1.78 & 1.04 & .18 & .21 \\
\hline I don't have to talk and can just listen if I want & 3.10 & 1.38 & $.30^{* * * *}$ & .05 \\
\hline \multicolumn{5}{|l|}{ Internet strengthened maladaptive beliefs } \\
\hline \multicolumn{5}{|l|}{ Internet use has led to } \\
\hline Belief that others view social anxiety as a weakness & 2.05 & 1.31 & .16 & .06 \\
\hline $\begin{array}{l}\text { Belief that others will be critical and reject those } \\
\text { with social anxiety }\end{array}$ & 2.08 & 1.22 & $.35^{* * *}$ & .02 \\
\hline Distrust of people & 1.54 & 1.10 & .16 & .08 \\
\hline $\begin{array}{l}\text { Belief that others have better social skills than those } \\
\text { with social anxiety }\end{array}$ & 2.74 & 1.42 & $.31^{* * * *}$ & .06 \\
\hline Misinformation about treatments for social anxiety & 1.51 & 1.01 & .04 & .03 \\
\hline \multicolumn{5}{|l|}{ Fear of negative evaluation on the internet } \\
\hline \multicolumn{5}{|l|}{ Internet use has led to } \\
\hline Fear interacting on the internet due to lack of feedback & 1.60 & .99 & .10 & -.08 \\
\hline Fear that internet communications will be misunderstood & 1.68 & .99 & .09 & -.11 \\
\hline $\begin{array}{l}\text { Increased observance and decreased participation on } \\
\text { the internet }\end{array}$ & 3.39 & 1.34 & $.24^{* * * *}$ & $-.24^{* * *}$ \\
\hline Fear of negative evaluation of internet communications & 2.89 & 1.25 & $.40^{* * *}$ & -.03 \\
\hline $\begin{array}{l}\text { Discomfort that others are observing my internet } \\
\text { discussions }\end{array}$ & 2.08 & 1.27 & $.27^{* * * *}$ & .03 \\
\hline $\begin{array}{l}\text { Belief that those with social anxiety should be } \\
\text { cautious about using the internet }\end{array}$ & 2.50 & 1.48 & .08 & .01 \\
\hline
\end{tabular}

Note. $N=354$. SIAS $r=$ correlation between the Social Interaction Anxiety Scale and individual items representing the self-rated negative effects of internet use. Time $r=$ correlations between the hours per week internet respondents reported interacting on the internet and individual items representing the self-rated negative effects of internet use. Items concerning the negative effects of internet use were rated on a 5-point Likert-type scale, from 1 (not true for me) to 5 (extremely true for $m e)$. Bonferroni-corrected $P$-values of $.004(.05 / 11), .008(.05 / 6)$, and $.01(.05 / 5)$ were employed in these analyses.

$$
\text { *** } P<.001 \text {. }
$$


degree to which these reported problems were associated with SIAS scores and the amount of time per week reportedly spent interacting on the internet. On average, internet respondents with social anxiety disorder reported that it was "moderately" to "very" true that internet use has led to increased passive observance and decreased active participation on the internet $(M=3.39$, S.D. = 1.34); and that they use the internet because they experience greater comfort interacting on the internet than face-to-face $(M=3.41$, S.D. $=1.40)$, because they don't have to talk and can just listen $(M=3.10$, S.D. $=1.38)$, because they have more time to think about what they want to say while using the internet than face-to-face $(M=3.02$, S.D. $=1.38)$, and because others cannot see visible signs of their anxiety $(M=3.14$, S.D. $=1.49)$.

SIAS scores were positively correlated with endorsement of most aspects of using the internet that may enable avoidance of face-to-face interactions (e.g., feeling that it is easier to interact on the internet and avoid face-to-face interactions; being able to passively observe the interactions of others; concealing physical appearance, mistakes in speech, and visible signs of anxiety; and having more time to think about what to say than in a face-to-face conversation). Further, SIAS scores were positively correlated with endorsement of aspects of using the internet that may entrench further maladaptive beliefs (e.g., internet use has led to a belief that others are critical and rejecting of those with social anxiety and that others have better social skills than do those with social anxiety). Finally, SIAS scores were positively correlated with endorsement of aspects of using the internet that may be associated with fear of negative evaluation from others on the internet (e.g., fear of negative evaluation of internet communications; discomfort that others are observing internet discussions; and increases in passive observance and decreases in active participation on the internet).

The amount of time per week reportedly spent interacting on the internet was positively associated with endorsement of aspects of using the internet that may enable avoidance of face-to-face interactions (e.g., feeling that it is easier to interact and share difficulties on the internet and avoid face-to-face interactions). Conversely, the amount of time per week reportedly spent interacting on the internet was associated with decreases in passive observance and increases in active participation on the internet.

\section{Discussion}

The current study demonstrates the feasibility of examining social anxiety using an internet-based survey and describes the nature of social anxiety, associated impairment, and correlates of internet use among socially anxious individuals seeking information on the internet about social anxiety disorder and its treatment. One goal of the present study was to explore the symptom profile of individuals seeking information on the internet about social anxiety disorder and its treatment. Given that the survey was attached to an anxiety disorders clinic 
homepage and the subject of the survey was identified as social anxiety, we expected that the majority of individuals participating would report significant symptoms. This proved to be the case, with $92 \%$ of internet respondents who provided complete information exceeding the recommended cut-off score for social anxiety disorder on a standardized assessment instrument. We were surprised, however, by the degree of social anxiety and associated impairment reported by the internet sample. Internet respondents with social anxiety disorder were more likely to have the generalized subtype of social anxiety disorder (as determined by a recommended cut-off score on a standardized assessment instrument) than the individuals who had actually presented for treatment at our clinic. In addition, internet respondents with social anxiety disorder rated themselves as experiencing more severe social anxiety and current impairment by a magnitude of half of a standard deviation or more than the individuals who had presented for treatment at our clinic.

Compared with individuals with social anxiety disorder in the community assessed in the National Comorbidity Survey (NCS; Kessler et al., 1994), internet respondents with social anxiety disorder were almost twice as likely to have never married, but appeared similar on age, sex, and race. Internet respondents with social anxiety disorder who resided predominately on the North American continent at the time they completed the study $(n=371)$ reported an unemployment rate $(11.59 \%)$ two or three times greater than the U.S. national unemployment rate that was reported for the time the current study was conducted (range: 4.0-4.8\% for 19992001; Bendull, 2002), despite the fact that they were almost twice as likely to have graduated from college than individuals with social anxiety disorder in the NCS (Kessler et al., 1994). Further, more than $70 \%$ of internet respondents reported anxiety, impairment, and distress in all situations surveyed except for eating in public, writing in public, and using public restrooms. More than three-fourths of internet respondents reported that they socialize in person less than five hours per week; more than one third reported having no significant friendships; and almost one half reported having no significant romantic relationships. In many ways, the characteristics of our internet sample echo the findings of Houston, Cooper, and Ford (2002) in their study of individuals participating in an internet support group for depression. Their internet sample consisted of individuals who were more chronically depressed, more socially isolated, and more likely to be unemployed and unmarried than primary care patients with major depression.

Moreover, a substantial proportion of the socially anxious individuals in the current internet survey sample were more anxious, impaired, and isolated than those represented in our clinic sample and may have been too anxious to seek information about social anxiety disorder and its treatment in ways that require social interaction (e.g., asking their primary care physician). Approximately onethird of internet respondents with social anxiety disorder reported having received psychotherapy, and about one-third reported having received pharmacotherapy for social anxiety disorder. Interestingly, a similar number reported trying herbal remedies, which have no empirical support in the treatment of social anxiety 
disorder but which may be obtained with relatively little social interaction. Thus, there may be a population of individuals with very severe social anxiety who are not well represented in clinical and epidemiological studies of social anxiety disorder and who are likely not to have received adequate (i.e., empiricallysupported) psychotherapy or pharmacotherapy.

Internet usage appears to have both benefits and costs for socially anxious individuals. Socially anxious internet users only slightly agreed with statements that they derive social support from internet interactions. Spending more time on the internet was associated with perceiving stronger social support and encouragement online and with developing increased confidence and new friendships in face-to-face interactions. Nonetheless, these benefits may come at the cost of weaker face-to-face social bonds. Internet respondents who reported spending the most time on the internet also reported feeling more comfortable interacting on the internet than face-to-face and spending more time talking about their problems to people on the internet than people in their lives away from the computer.

Although socially anxious internet participants strongly agreed that they had learned new things about social anxiety disorder and its treatment on the internet, they only slightly agreed that their internet usage had led them to actually take actions such as seeking psychotherapy or seeking medication, perhaps because either of these options still requires a good deal of face-to-face interaction. Greater social anxiety was correlated with endorsing having learned about social anxiety and its treatment on the internet, but not with taking action to receive treatment based on what was learned.

As previously described, contemporary cognitive-behavioral models of social anxiety disorder propose that affected individuals, when confronted with an audience, form negatively biased images of how they imagine that they appear to others (Clark \& Wells, 1995; Rapee \& Heimberg, 1997). Thus, we predicted that socially anxious internet users would find internet communication attractive because it can conceal physical appearance and aspects of behavior typical of face-to-face interactions that they may view as making negative evaluation by others more likely. Consistent with this hypothesis, there was moderate agreement with items suggesting that the internet is a desirable form of communication because it allows for avoidance of feared aspects of face-to-face social interactions (e.g., the internet allows one to conceal physical appearance, mistakes in speech, lags in conversations, visible signs of anxiety). The individuals with the greatest social anxiety most strongly endorsed these items as being true of them.

According to cognitive-behavioral models of social anxiety (Clark \& Wells, 1995; Rapee \& Heimberg, 1997) and fear reduction (Foa \& Kozak, 1986), partial exposure, in which the most feared aspects of a social interaction are avoided, is unlikely to provide the corrective information needed to reduce anxiety, modify negatively biased mental images of the self, or decrease estimates of the likelihood of negative evaluation by others. Indeed, individuals reporting the greatest social interaction anxiety do not appear to experience a respite from their evaluative concerns while interacting with others on the internet. They reported 
higher levels of passively observing internet interactions, greater avoidance of face-to-face interactions, fear of negative evaluation of their internet communications, and discomfort regarding being observed during internet discussions. Such partial exposure may undercut motivation for potentially more beneficial face-toface exposures. In fact, the most socially anxious individuals were most likely to report that their internet interactions made it easier for them to avoid face-to-face interactions. Furthermore, existing beliefs that other people are critical or rejecting may be reinforced through internet communications. More severe social interaction anxiety was associated with entrenchment of beliefs that others are critical and rejecting of those with social anxiety and have better social skills.

The findings of the current study may suggest that a subgroup of individuals with social anxiety disorder has carved out a separate, more tolerable social world on the internet. Strikingly consistent with the findings reported by Kraut and colleagues (2002), individuals with social anxiety disorder who spent the largest amount of time interacting on the internet were more likely to report greater comfort with internet interactions and greater reliance upon the internet as a social outlet to the exclusion of face-to-face interactions. These individuals were more likely to report greater comfort initiating and maintaining conversations with others on the internet than face-to-face and to prefer discussing their problems with others on the internet to interacting face-to-face socially or with a treatment provider. Taken together, it appears as though individuals with the most severe social anxiety disorder may gain comfort with cyberspace interactions, particularly if they spend greater amounts of time doing so. However, these gains may prove to be elusive, belying greater isolation, anxiety, and impairment associated with non-cyberspace interactions, and greater misinformation and entrenchment of maladaptive beliefs.

Certainly, a prospective study among internet users with social anxiety disorder will more clearly describe changes in social anxiety, impairment, treatment seeking, and internet use over time so as to better inform clinical practice and internet-based interventions. The current study suggests that social anxiety disorder websites currently may be invaluable in providing psychoeducation about social anxiety disorder to individuals who would otherwise be bereft. That the current investigation's internet respondents evidenced sufficient motivation and knowledge to locate anxiety disorder websites, which provided links to the survey, suggests the potential utility of the internet, in general, and anxiety disorder websites, in particular, to provide psychoeducation and to correct misinformation (e.g., about consequences of avoiding anxiety-provoking situations). Associations between social interaction anxiety, amount of time spent on the internet, and respondents' perception of the internet's influence on their social anxiety suggest that internet respondents with more severe social interaction anxiety and who more frequently rely on the internet as a social outlet may be likely to acquire new information about social anxiety, to gain an understanding that social anxiety disorder is treatable, to learn about psychotherapy and pharmacotherapy for social anxiety disorder, and to receive greater encouragement when sharing difficulties 
with social anxiety through internet use. However, such websites may also emphasize the ways in which the internet can be a possible contributor to avoidance of face-to-face interactions, entrenchment of maladaptive beliefs, and fear of negative evaluation. In addition, those providing treatment to individuals with social anxiety disorder may find it useful to remain cognizant of and address in treatment these potential negative correlates of internet use, the likelihood of which appears to increase as social interaction anxiety and internet use increase.

When working with patients who interact with others on the internet, treatment providers also may capitalize on the existence of the established Internet-based social world by including cyberspace interactions in the development of a fear hierarchy and of cognitive and exposure exercises. Speculatively, guided exposure to revealing more of one's physical appearance through use of stylized avatars and photographs in chat room and discussion group interactions could lead to realtime video interactions via a quickcam and finally to face-to-face interactions. Voicebased chat with and without photo or video images also may be used in a similar way, and virtual therapists may be introduced into this environment. Bringing treatment for social anxiety disorder into cyberspace may increase the chances that some of these individuals will pursue empirically supported treatments, which requires face-to-face social interaction.

This study demonstrates the feasibility of conducting internet-based research among individuals with social anxiety disorder and hopefully encourages other internet-based studies such as prospective and psychoeducation-oriented intervention studies. Intervention studies in particular may be of critical importance, especially for individuals who reside in areas where there are few or no clinicians trained in empirically-based treatments. However, given the nature of internetbased research, there are several limitations to the current investigation. First, use of the internet as a means of survey data collection introduces bias since sampling is not random and since it is unlikely that individuals who use the internet are representative of the general population. For instance, internet users have been found to be younger, better educated, more affluent, and less likely to belong to a minority group than those who do not use the internet (e.g., Rhode \& Shapiro, 2000). Indeed, in the current investigation, the large majority of internet respondents described themselves as Anglo and residing in North America. Although individuals with social anxiety who utilize the internet represent the population of interest in the current investigation, it is acknowledged that the findings of the current study may not generalize to those who are less likely to have access to the internet, less inclined to seek information about social anxiety disorder from the internet, or less motivated to fill out surveys posted on the internet. Second, although the data were screened for multiple identical responses, because potential internet respondents were assured that anonymity would be maintained, it was not possible to identify multiple non-identical responses submitted by the same individual. Third, also because potential internet respondents were assured that anonymity would be maintained, it was not possible to confirm the authenticity of the respondents or their submissions. Fourth, comparisons of internet use 
and endorsement of psychiatric symptoms among persons with social anxiety disorder with those of other clinical populations are necessary to determine the specificity of the findings of the current study to social anxiety disorder. Fifth, follow-up assessments were not included in the current investigation; therefore, it is not yet possible to determine whether or how social anxiety, internet use, and treatment-seeking change over time among socially anxious internet users. Finally, these data must be interpreted in the context of the time in which they were collected (December 1999 through July 2001). At the time of data collection, internet interaction was characterized largely by text-based interfaces in which people would converse either in real time or at temporally distant times by means of typing. As machines get quicker and cheaper, broadband connections become more widely available, and computer-based video and audio peripherals become less expensive, it would be expected that these methods of internet interaction would increase. The degree to which audio and video interactions will be used or avoided by individuals with social anxiety disorder remains to be seen-will they remain in a text-based environment or will their comfort with the electronic medium help ease them into more media rich interactions that more closely resemble face-to-face contact?

\section{References}

Bendull, B. F. (2002). Historical labor force/unemployment data for the United States [On-line]. Available: http://www.nidataplus.com/lfeus1.htm\#annl. Labor Market Information Unit, Indiana Department of Workforce Development.

Brown, E. J., Turovsky, J., Heimberg, R. G., Juster, H. R., Brown, T. A., \& Barlow, D. H. (1997). Validation of the Social Interaction Anxiety Scale and the Social Phobia Scale across the anxiety disorders. Psychological Assessment, 9, 21-27.

Clark, D. M., \& Wells, A. (1995). A cognitive model of social phobia. In: R. G. Heimberg, M. R. Liebowitz, D. A. Hope, \& F. R. Schneier (Eds.), Social phobia: diagnosis, assessment, and treatment (pp. 69-93). New York: Guilford Press.

Cummings, J. N., Butler, B., \& Kraut, R. (2002). The quality of online social relationships. Communications of the ACM, 45, 103-108.

Cummings, J. N., Sproull, L., \& Kiesler, S. B. (2002). Beyond hearing: where real-world and online support meet. Group Dynamics: Theory, Research, and Practice, 6, 78-88.

Dillman, D. A., Totora, R. D., Conradt, J., \& Bowker, D. (1998, August). Influence of plain versus fancy design on response rates for web surveys. Paper presented at Joint Statistical Meetings, Dallas, TX.

DiNardo, P. A., Brown, T. A., \& Barlow, D. H. (1994). Anxiety Disorders Interview Schedule for DSM-IV: Lifetime Version (ADIS-IV-L). San Antonio, TX: The Psychological Corporation.

Foa, E. B., \& Kozak, M. J. (1986). Emotional processing of fear: exposure to corrective information. Psychological Bulletin, 99, 20-35.

Global Reach. (2003, May 28). Global Internet Statistics (by language). Retrieved from www.glreach.com.

Gross, E. F., Juvonen, J., \& Gable, S. L. (2002). Internet use and well-being in adolescence. Journal of Social Issues, 58, 75-90.

Hambrick, J. P., Turk, C. L., Heimberg, R. G., Schneier, F. R., \& Liebowitz, M. R. (in press). Psychometric properties of disability measures among patients with social anxiety disorder. Journal of Anxiety Disorders. 
Hambrick, J.P., Turk, C.L., Heimberg, R.G., Schneier, F.R., \& Liebowitz, M.R., (2003). The experience of disability and quality of life in social anxiety disorder. Depression and Anxiety 18, 46-50.

Hart, T. A., Fresco, D. M., Turk, C. L., \& Heimberg, R. G. (2000). Using self-report measures to identify social anxiety disorder and its subtypes: a receiver operating characteristic analysis. Unpublished manuscript.

Heimberg, R. G., Mueller, G. P., Holt, C. S., Hope, D. A., \& Liebowitz, M. R. (1992). Assessment of anxiety in social interaction and being observed by others: the Social Interaction Anxiety Scale and the Social Phobia Scale. Behavior Therapy, 23, 53-73.

Hills, P., \& Argyle, M. (2003). Uses of the internet and their relationships with individual differences in personality. Computers in Human Behavior, 19, 59-70.

Houston, T. K., Cooper, L. A., \& Ford, D. E. (2002). Internet support groups for depression: a 1-year prospective cohort study. American Journal of Psychiatry, 159, 2062-2068.

Kessler, R. C., McGonagle, K. A., Zhao, S., Nelson, C. B., Hughes, M., Eshleman, S., Wittchen, H. U., \& Kendler, K. S. (1994). Lifetime and 12-month prevalence of DSM-III-R psychiatric disorders in the United States: results from the National Comorbidity Survey. Archives of General Psychiatry, 51, 8-19.

Kraut, R., Kiesler, S., Boneva, B., Cummings, J., Helgeson, V., \& Crawford, A. (2002). Internet paradox revisited. Journal of Social Issues, 58, 49-74.

Kraut, R., Patterson, M., Lundmark, V., Kiesler, S., Mukopahdyay, T., \& Scherlis, W. (1998). Internet paradox: a social technology that reduces social involvement and psychological well-being? American Psychologist, 53, 1017-1031.

Mattick, R. P., \& Clarke, J. C. (1998). Development and validation of measures of social phobia scrutiny fear and social interaction anxiety. Behaviour Research and Therapy, 36, 455-470.

Rajala, A. K., \& Hantula, D. A. (2000). Towards a behavioral ecology of consumption: delay reduction effects on foraging in a simulated online mall. Managerial and Decision Economics, $21,145-158$.

Rapee, R. M., \& Heimberg, R. G. (1997). A cognitive-behavioral model of anxiety in social phobia. Behaviour Research and Therapy, 35, 741-756.

Rhode, G. L., \& Shapiro, R. J. (2000). Falling through the net: towards digital inclusion. Washington, DC: US Department of Commerce National Telecommunications and Information Administration.

Rose, G., Lees, J., \& Meuter, M. (2001). A refined view of download time impacts on e-consumer attitudes and patronage intentions toward e-retailers. International Journal of Media Management, 3, 105-111.

Schneier, F. R., Heckelman, L. R., Garfinkel, R., Campeas, R., Fallon, B. A., Gitow, A., Street, L., Del Bene, D., \& Liebowitz, M. R. (1994). Functional impairment in social phobia. Journal of Clinical Psychiatry, 55, 322-331.

Stein, M. B., Walker, J. R., \& Forde, D. R. (1994). Setting diagnostic thresholds for social phobia: considerations from a community survey of social anxiety. American Journal of Psychiatry, 151, 408-412.

Swickert, R. J., Hittner, J. B., Harris, J. L., \& Herring, J. A. (2002). Relationships among internet use, personality, and social support. Computers in Human Behavior, 18, 437-451.

Turner, S. M., Beidel, D. C., Dancu, C. V., \& Keys, D. J. (1986). Psychopathology of social phobia and comparison to avoidant personality disorder. Journal of Abnormal Psychology, 95, 389-394.

Whisman, M. A., Sheldon, C. T., \& Goering, P. (2000). Psychiatric disorders and dissatisfaction with social relationships: does type of relationship matter? Journal of Abnormal Psychology, 109, 803-808.

Wittchen, H., Fuetsch, M., Sonntag, H., Muller, N., \& Liebowitz, M. (1999). Disability and quality of life in pure and comorbid social phobia: findings from a controlled study. European Psychiatry, $14,118-131$. 